\title{
A comparative study on the influence of sci-tech journals
}

\author{
Kan Li \\ Jiefang Road 667, Dalian Naval Academy, Dalian, China \\ likandl@126.com
}

Key words: sci-tech journals; impact factor; developing suggestions

\begin{abstract}
Aiming at the current situation of less influence of Chinese sci-tech journals, this paper analyzed the inscape of journals' influence, and carried out a compare analysis between the sci-tech journals with the literature material law and correlation method. And it also proposed the related suggestion for improving the influence of sci-tech journal. Therefore, this paper has certain reference value for strengthening total quality management of sci-tech journal and improving propagation effects of sci-tech information.
\end{abstract}

\section{Introduction}

Sci-tech journal plays a significant role in the development of scientific and technology, and the degree of development of sci-tech journal directly reflects the activity of national scientific research activities and the prosperity of the development of scientific and technology. Since the turn of the century, the development of scientific and technology goes ahead through rapidly, so that the development of sci-tech journal presents a piece of prosperous scene, the species and mummers have soared. Compared with the developed countries, such as US, United Kingdom, Netherlands and Germany, and so on, the whole quality and influence of journals exists some obvious problems of quality weakening and low influence. So, it is necessary to deeply analyze the problems of lack of institutional and entity responsibility, which prevent the development of Chinese sci-tech journals, and this paper also discussed the suggestions for adapt to the Chinese characteristics.

\section{Basic overview on influence on sci-tech journals}

\subsection{Basic definition}

Sci-tech journal is a kind of journal that can publish papers of nature science and technology, and is the main form that can record the historical development of science and technology, and is also an important part of knowledge innovation. So, it has important status in science and technology. The influence power of sic-tech journal refers to the academic research achievements have been published in this journal within a specified period of time, which have certain influence for the development of scientific research in this field and the technology promotion. Sci-tech journal is a carrier of publish, which record the scientific achievements. Scti-tech journal has higher influence power, which reflects the level of scientific research of this country to sine extent. To improve the influence power of sci-tech journal is the common working goals of government agency, working field, sponsor units and editing group.

\subsection{Component factor and causal relationship}

The main evaluation indexes of journal impact are total citations, impact factors, immediacy index and clout index. Total citations in the current year refer to the total times that all the papers published in some journal over the years are cited in the current year, representing the general rough evaluation. The impact factors in the current year refer to the ratio of the times that the papers published in the previous two calendar years are cited in the current year to the total number of papers published in these two years, representing the influence in these two years. The immediacy index refers to the ratio of the times that the papers published in the current year are cited in the 
same year to the number of papers published in the same year, representing the influence in the current year. The clout index refers to the value obtained through the vector parity after the linear normalization of impact factors and total citations of the journal, representing comprehensive evaluations on the influence of a journal. From the popular and general perspectives, total citations and actual circulations have a direct impact on the influence of scientific journals. In other words, with the increase in the times that the papers in one journal are cited, the influence of journal becomes stronger and stronger, and its circulation increases gradually. In addition, the ratio of funded papers is also one element of influence. In general, the funded research projects are characterized by innovation, in-depth research and high academic value; so to increase the publication rate of the funded papers can naturally enhance the influence of a journal.

\section{Analysis on influence of sci-tech journal}

\subsection{Development status of sci-tech journal}

Socioeconomic development and science and technology process is getting better on the whole, which can provide a good platform environment for the construction and operation of sci-tech journal. At present, the number of Chinese sci-tech journals is all on the top levels in international ranking, and already is the world's second biggest journals publishing producer, and forms a relatively perfect system including the various disciplines. And the mode of digitization, networked and profit mode of journals have formed initially. But compared to the United States, the development of Chinese sci-tech journal exist many problems, such as the stagnancy of management, the loss of high quality article and the low of market-oriented level. And the sci-tech journal with high quality and high international influence is very scarce, the journal are included in SCI is also very little. And the average impact factor and average citation frequency are far below international population mean. So, Chinese sci-tech journals are still faces complex development form and serious challenge.

\subsection{Difference of influence of journals}

To analyze the international influence of China's technical journals, the internationally recognized clout index (Ic) should be used, which can comprehensively reflect the international academic level of the journal and its influence. The algorithm formula is as follows:

$$
I_{c}=\sqrt{2}-\sqrt{\left(1-I_{f}\right)^{2}+\left(1-T_{c}\right)^{2}}
$$

$I_{f}$ and $T_{C}$ respectively represent the impact factor and total citation of some journal after the standardization through the linear normalization.

The international clout index of English technical journals in China is analyzed as an example. Figure 1 shows that total citations and impact factors of the English technical journals have grown continuously and stably during the period of from 2011 to 2014. It can be seen from the growth indicators that the English technical journals in China present a good development trend.

In the contrastive analysis of China's technical journals and SCI in this paper, in order to ensure the intuitiveness and fairness, the authors mainly adopt the statistical data provided through dual-logarithm coordinates system and unified statistical source. The coordinate shows that, the SCI attaches importance to the impact factor. Meanwhile, the impact factor and total citation are positively correlated. Therefore, the SCI can achieve a higher academic influence and academic value. But for China's technical journals, their focus is mainly on the times of citations, times of excerpts, retrieval amount, Web downloads and the number of funded papers; so the impact factors are neglected to some extent. The development gap between China's outstanding technical journals and SCI journals is not limited to the content shown in the coordinate. In order to narrow the development gap between China's technical journals and SCI journals, the systematic measures 
should be taken centering on the impact index to comprehensively enhance the influence of technical journals in China.

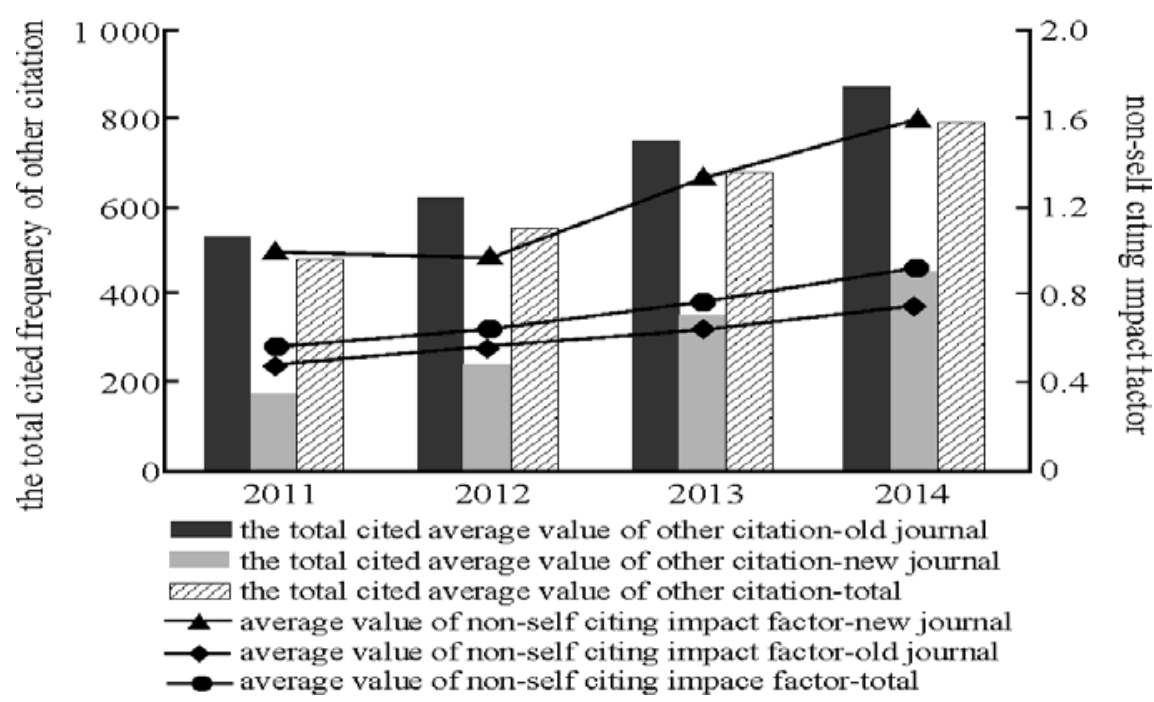

Figure 1. International influence factor of China English journal

\section{Some suggestions for improving influence of sci-tech journal}

\subsection{To enhance the strength of scientific and technology is foundamental}

To enhance the strength and level of science and technology is the fundamental to fundamentally improve the core influence of Chinese sci-tech journal. Although, sci-tech level of China has made great progress, but the academic value of scientific papers is still relatively low compared with the developed countries, which seriously affected the improvement of Chinese sci-tech journal. Only by improving sci-tech level, can we improve the academic development and improve the quality of sci-tech quality. So, China should enlarge the degree of talent selection; cultivate the sci-tech talents team from various angles. At the same time, the scientific and technical workers should carry forward the scientific spirit, so as to improve the level of science and technology of China.

\subsection{To strengthening national policy guidance is the key problem}

The government provided policy guidance in the aspects of cultural and information industry, industry and agriculture, and so on. But the sci-tech journal is relatively weak in aspect of policy guidance and support force. The evaluation system of scientific research of China is not yet perfect. The important of sci-tech journal is far less than the application of database. So, the number and species of Chinese excellent journals is slower in developing speed. Therefore, to strengthen the policy guidance of government is the key to promote the development of sci-tech journal.

First, To deal with the relationship between marketization and commonweal, if the sci-tech journal has an absolute marketization, the attention of the journal is change with the variation of market, at the same time, it will be more social problems. If the sci-tech journal has an absolute commonweal, so the periodical press and author will be influence in the aspects of efforts and creativity. So, this relationship can't be understood the maketization or commonweal, it should be realize the good combination of the two according to the actual content and application target. Only in this way, so that can improve the competitiveness and influence.

The second is to unified the publishing platform of sci-tech journal, the net work platform of sci-tech journal of China is no unifying plan, including the larger platforms of china national knowledge infrastructure, wan fang database, longyuan journal, Chongqin weipu, china journal net and china academic journals full-text database, and so on, and there are small platforms to constantly appearing, which reduce the propagation efficiency, and there is no uniform evaluation standard has influence on the improvement of total quality of sci-tech journal. Publishing platform 
of international journal, such as SCI, EI, ISTP, and advanced database are worth to learn for China. So, China should construct the authoritative journal publishing platform, it will not only realize the effective protection of sci-tech resources, but also can improve the influence of journal.

The third is innovated the development model of journal management. It should be broken the limit of traditional journal publishing model, the future development trend of journal is diversification, specialization and systematization. We must encourage the fusion and creative development of journal, must innovate the management and development model of sic-tech journal. So, we can expand the model of journal and improve the influence power of journal, so as to improve the economic benefits of sponsor. At the same time, we can build a diversified policy environment and cultural environment for the development of journal.

The fourth is to establish and develop the related management policy for the evaluation of journal. It should be established the academic confidence, and build a health and comfortable environment for the development of sci-tech journal. And it cannot rely on the western country. So, it should establish evaluation management system sci-tech journal and establish the quality evaluation system for sci-tech papers, so as to evaluate an exanimate the scientific papers of scientific research personnel, university teachers and college students. Therefore, it can improve the evaluation weights of published papers of domestic sci-tech journals and improve the domestic proportion of high quality papers.

Fifth, it is to do all the preparatory work for international journal. We should learn the worthy reference of foreign excellent journal, and introduce it into China, so as to learn from it and too cultivate the journals adapt to the characteristics of China, which can make our journals to join the communication system of international high-academic. Based on this, we should promote the orderly development of journal industry and show the strength of science and technology of China in aspects of characteristic of journal, information content and achievements extension. By taking the international journal as the guidance, journals should be more and more specialization and professionalization in order to meet the needs of whole industry of journals.

\subsection{To establish the team for periodical running is the breakthrough}

The construction of editorial team is the key of the construction of journals quality. Editor staff is the goalkeeper for the in each production phase for journal publishing, where they duties consisted chiefly of implement of editorial standardization and quality of published content. So, it is necessary to strengthen the cultivation and selection of editor staff, and to focus on the rational proportion for the editing professionals and sci-tech professionals, and build an editor echelon with high quality and appropriate scales. Editor staff team is full of vitality by improving training and assessment regulations and establishing mechanism for selecting the superior and eliminating the inferior and implementing dynamic management.

\section{Conclusions}

The survival environment of sci-tech journal is closely bound up to the scientific and production. Accelerating development of national innovation system can make the constant innovation achievement, which provided a chance for the development of sci-tech journals. The fate of sci-tech journals publishing industry mainly depend on competitiveness, to improve the quality of journal is the most critical to improve the influence of journal.

\section{References}

[1] WU Hongjun, XIAO Hong. Statistical analysis of the international influence of Chinese scitech journals [J], Acta Editologica,2013,25(5):507-510.

[2] LI Kan Sato Study on TQM theoretical model for science and technology journals [J], Chinese Journal of Scientific and Technical Periodicals, 2017, 28(3):220-224.

[3] XIE Xinzhou. Competitiveness evaluation of sci-tech journal[J],Beijing: Huaxia publishing house, 2013:15-248 